\title{
Cadmium uptake by the moss, Calymperes delessertii, Besch
}

\begin{abstract}
Studies were conducted to assess the capability of a moss, Calymperes delessertii Besch, in removing cadmium from solutions. In the batch experiments, parameters studied included $\mathrm{pH}$, sorbent dosage, cadmium concentration, ionic strength, presence of other ions, temperature and contact time. In addition, a series of fixed-bed experiments was performed to study the flow system in an attempt to simulate industrial conditions. The bed depth service time (BDST) model proposed by Hutchins was successfully applied to the system. The results show that the moss is an efficient sorbent for cadmium from solution and that the mechanism of sorption is mainly an ion-exchange process.
\end{abstract}

Keyword: Moss; Cadmium; Aqueous solution; Uptake; Absorption characteristics 